\title{
Yüksek Gerçeklikli Hasta Simülatöründe Eğitim: Hemşirelik Öğrencilerinin Memnuniyeti ve Öğrenmede Kendine Güvenlerinin Değerlendirilmesi
}

\author{
Elif Karahan $^{1 *}$, Sevim Çelik² ${ }^{2}$ Dilek Yıldım Tank ${ }^{1}$, Fatih Göğüşs \\ ${ }^{1}$ Zonguldak Bülent Ecevit Üniversitesi Sağlık Bilimleri Fakültesi, Hemşirelik Bölümü, Cerrahi Hastalıkları \\ Hemşireliği Anabilim Dalı Zonguldak, Türkiye \\ ${ }^{2}$ Tokat Gaziosmanpaşa Üniversitesi Palyatif Bakım Uygulama ve Araştırma Merkezi, Tokat, Türkiye \\ elifim67@yahoo.com, sevimakcel@yahoo.com,dilek8488@windowslive.com, fatihgögüs@yahoo.com \\ Orcid:0000-0002-6371-871X \\ Orcid:0000-0002-2016-5828 \\ Orcid:0000-00017966-5395 \\ Orcid:0000-0003-0283-0094 \\ *Sorumlu Yazar / Corresponding Author: Elif Karahan \\ Gönderim Tarihi / Received:19.04.2019 \\ Kabul Tarihi / Accepted: 19.06.2019 \\ DOI: $10.34087 /$ cbusbed.528867
}

\begin{abstract}
Öz
Amaç: Bu çalışmanın amacı, yüksek gerçeklikli hasta simülatöründe uygulama yapan hemşirelik öğrencilerinin memnuniyeti ve öğrenmede kendine güvenlerini tanımlamaktır.

Yöntem: Araştırmanın örneklemini çalışmaya katılmayı kabul eden ikinci sınıf düzeyindeki toplam 130 öğrenci oluşturdu. Veri toplama aracı olarak öğrenci tanıtım formu ve Öğrenci Memnuniyeti ve Öğrenmede Kendine Güven Ölçeği kullanıldı. Verilerin değerlendirilmesinde sayı, yüzde, ortalama gibi tanımlayıcı istatistiksel yöntemler kullanıldı.

Bulgular: Öğrenci Memnuniyeti ve Öğrenmede Kendine Güven Ölçeği’nden öğrencilerin $50.32 \pm 8.65$ puan aldıkları belirlendi. Öğrencilerin ölçeğin memnuniyet alt bölümünden $20.72 \pm 4.00$ puan aldıkları saptandı. Öğrencilerin eğitim sonrası ölçeğin güven alt boyutu bölümünden ortalama $29.60 \pm 4.98$ puan aldıkları bulundu.

Sonuç: Çalışma bulguları, öğrencilerin yüksek gerçeklikli hasta simülatörü eşliğinde yapılan eğitimden oldukça memnun olduklarını ve özgüvenlerin gelişmesinde simülasyon eğitiminin etkili olduğunu gösterdi.

Anahtar kelimeler: Simülasyon, Hemşirelik Öğrencisi, Kendine Güven, Memnuniyet.
\end{abstract}

Abstract
Aim: The aim of this study is to describe the satisfaction and self-confidence of nursing students who practice in a high-reality patient simulator.

Method: The sample of the study consisted of 130 second grade students who agreed to participate in the study. Student Identification Form and Student Satisfaction and Self-Confidence in Learning Scale were used as data collection tools. In the evaluation of data, descriptive statistical methods such as number, percentage and average were used.

Results: It was determined that the students got $50.32 \pm 8.65$ points from the Student Satisfaction and in Learning Scale. It was determined that the students got $20.72 \pm 4.00$ points from the satisfaction subscale of the scale. It was found that the students got an average of $29.60 \pm 4.98$ points from the self-confidence subscale of the scale.

Conclusion: The findings of the study showed that the students were very satisfied with the training performed with the high-reality patient simulator and the simulation training was effective in the development of self-confidence.

Key words: Simulation, Nursing Student, Self-Confidence, Satisfaction.

\section{Giriş}

Günümüzde, simülasyon yöntemi hemşirelik ve diğer sağlık profesyonelleri tarafından giderek artan bir şekilde kullanılmaya başlanmıştır. Yenilikçi interaktif yöntemlerden biri olan simülasyon, öğrencilere gerçek yaşam durumlarını klinik senaryolar aracılığı ile pratik deneyim kazanma firsatı sağlayan bir yöntemdir. Klinik eğitim hemşirelik programında oldukça büyük bir öneme sahiptir. Klinik eğitim öncesi simülasyon kullanımı öğrencinin eğitime hazır oluşunun sağlanmasında etkili bir çözüm aracı olduğu kabul edilmektedir $[1,2]$. 
Hemşirelik eğitim programlarının yürütülmesinde klinik öğrenme ortamlarının yetersizliği, öğrenci sayılarının çokluğu ve hasta güvenliğini sağlama gibi nedenlerle geleneksel yöntemlerin yanı sıra simülasyon uygulamaları ile temel becerilerin kazandırılabileceği bildirilmektedir [1]. Gerçekçi klinik ortamların sağlanabilmesi ile öğrenci durumu daha kolay anlayabilir ve bakım yönetimi yapabilir. Yüksek gerçeklikli hasta simülatörü aracılığı ile öğrencilerin gerçekçi klinik senaryoları yönetmesi beklenmektedir. Gerçek yaşam ortamlarında ortaya çıkan nadir durumları beklemek yerine gerçekçi klinik öğrenme ortamının sağlandığı simülasyon ile öğrenci bilişsel, psikomotor ve davranışsal bilgi ve beceri geliştirilebilir ve bunun sürekliliği sağlanabilir [2].

Simülasyon yöntemi 40 yılı aşkın bir zamandır olmasına rağmen, son 10 yıldır klinik öğretim ve öğrenme stratejisinin ayrılmaz bir parçası olarak görülmüştür. Günümüzde düşük teknolojik özelliklere sahip tam vücut mankenleri veya maketler, standart simüle hastalar, sanal ve bilgisayar tarafindan oluşturulan simülasyon veya birkaç modelin kombinasyonu ile hibrit simülasyon gibi birkaç simülasyon modeli vardır [3]. Simülasyon laboratuarının kurulabilmesi ciddi yatırım gerektirmektedir. Ülkemizde de çok sınırlı sayıda simülasyon laboratuarı kurulmuş durumdadır. Tüm bu çabalara rağmen simülasyon ortamları yeterli ancak personel, eğitimsel faktörler, kaynak gelişimi, kaliteyi sürdürme gibi faktörlerin simülasyon deneyimini geliştirmede engel oluşturduğu literatürde bildirilmektedir [4].

Ülkemizde simülasyon uygulamalarına yönelik yapılan çalışma sonuçları sınırlı sayıdadır. Bu doğrultuda bu çalışmanın amacı, yüksek gerçeklikli hasta simülatöründe uygulama yapan hemşirelik öğrencilerinin memnuniyetini ve öğrenmede kendine güvenlerini tanımlamaktır.

\section{Yöntem}

Çalışma Tasarımı: $\mathrm{Bu}$ çalışma Batı Karadeniz Bölgesinde bulunan bir Sağlık Bilimleri Fakültesinin Hemşirelik Bölümünde Şubat- Haziran 2018 tarihleri arasında tanımlayıcı tasarımda yürütüldü.

Evren ve Örneklem: Çalışmanın evreni, çalışmanın yürütüldüğü Hemşirelik Bölümünde 2017-2018 eğitim öğretim yılı güz yarıyılında öğrenim gören ve simülasyon uygulamasına katılan 230 ikinci sinıf öğrencisidir. Evren bilinen örnekleme hesaplama yöntemi kullanılarak, \%5 kabul edilebilir hata ve $\% 90$ güven aralığında belirlenen örneklem sayısı 125'dir. Çalışmaya katılmayı kabul eden 130 öğrenci örneklemi oluşturdu.

Veri Toplama Araçları: Veri toplamada Öğrenci Tanıtım Formu ve Öğrenci Memnuniyeti ve Öğrenmede Kendine Güven Ölçeği kullanıldı. Öğrenci Tanıtım Formunda yaş ve cinsiyet soruları yer aldı. Öğrencilerin simülasyonla ilgili tutum ve inançlarını ölçmek için geliştirilen "Öğrenci Memnuniyeti ve Öğrenmede
Kendine Güven Ölçeğil" Ulusal Hemşirelik Birliği (National League for Nurses) tarafından yayınlanmıştır. Karaçay ve Kaya tarafından 2017 yılında Türkçe geçerlilik ve güvenirliği yapılan ölçeğin iç tutarlılık katsayısı 0.88 olarak bulunmuştur [5]. Ölçeğin “öğrenmeden memnuniyet" ve "kendine güven" olmak üzere iki alt boyutu olup toplam madde sayısı 13'tür. Ölçek beşli likert şeklinde yanıtlanmaktadır. Ölçekten alınan en az puan 17, en yüksek puan 61'dir.

Veri Toplama Yöntemi: Uluslararası Klinik Simülasyon ve Öğrenme Hemşireler Birliği’nin belirlediği standartlar çerçevesinde araştırmanın verileri topland. $\mathrm{Bu}$ standartlarda ölçülebilir hedefler doğrultusunda senaryo tasarlanması, katılımını sağlayacak kolaylaştırıcılar olması, ön bilgilendirme ve geri bildirim yer almaktadır [6]. Çalışmaya başlamadan önce öğrencilere gruplar halinde simülasyon laboratuarına alınacakları ve yapılan değerlendirmelerin bir başarı notu ile sonuçlanmayacağı açıklaması yapıldı. Simülasyon laboratuarının yapılabilmesi amacıyla araştırmacılar tarafından iki klinik senaryo yazıldı. Birinci senaryoda genel anestezi yapılan, ameliyat sonrası birinci gündeki hasta bakımını kapsamaktadır. İkinci senaryoda acil servise miyokart infaktüsü ile gelen hastaya yapılan ileri yaşam desteği girişimlerini kapsamaktadır (Tablo 1). Beşerli gruplar halinde simülasyon uygulaması yapıldıktan sonra veri toplama formları ile veriler topland1.

Verilerin Değerlendirilmesi: Elde edilen veriler SPSS 16.0 programina girilerek say1, yüzde, ortalama gibi tanımlayıcı istatistikler yöntemler ile değerlendirildi.

Etik Yaklaşım: Ölçeklerin kullanımı konusunda Türkçe geçerlilik ve güvenirliğini yapan yazarlardan eposta aracılığı ile izin alındı. Çalışmaya başlamadan önce çalışmanın yapılacağı kurumdan izin alındı. Gönüllülük esasına göre öğrenciler çalışmaya katıldı.

\section{Bulgular}

Çalışmaya katılan öğrencilerin yaş ortalamasının $20.01 \pm 1.14$ olduğu, cinsiyet dağılımı incelendiğinde \% 72.3'ünün kadın, \%27.7'sinin erkek olduğu belirlendi.

$\mathrm{Bu}$ çalışma için Öğrenci Memnuniyeti ve Öğrenmede Kendine Güven Ölçeğinin güvenilirlik analizi Cronbach's Alpha olarak hesaplandı ve değerler Tablo 2'de sunuldu. Buna göre öğrenci memnuniyeti iç tutarlılık değeri 0.93; öğrenmede kendine güven iç tutarlılık değeri 0.83 'tür.

Öğrencilerin Öğrenci Memnuniyeti ve Öğrenmede Kendine Güven Ölçeği'ne vermiş oldukları yanıtlar ve yüzdelik oranları Tablo 3'de sunuldu. Öğrencilerin memnuniyet ile ilgili maddelere 5 üzerinden ortalama olarak $4.14 \pm 0.80$ puan verdikleri saptand1. Bu sonuca göre öğrencilerin büyük bir çoğunluğunun simülasyon eğitiminden memnun oldukları belirlendi. Memnuniyet alt boyutunda yer alan "Simülasyonda kullanılan öğretim yöntemleri yararlı ve etkiliydi." maddesine $4.21 \pm 0.87$ ortalama ile en yüksek puan verildiği saptand1. 
Öğrencilerin öğrenmede kendine güven alt boyutu ile ilgili sorulara ortalama olarak 5 puan üzerinden $3.70 \pm 0.62$ puan verdikleri belirlendi. Bu simülasyondan ne öğrenmem gerektiğini bilmek öğrenci olarak benim sorumluluğumdur" maddesi $4.10 \pm 0.9$ puan ile en yüksek puan verilen maddedir.

Tablo 1. Simülasyon Maketinde Klinik Senaryoların Uygulanması

\begin{tabular}{|c|c|c|}
\hline \\
\hline \multicolumn{3}{|c|}{$\begin{array}{l}\text { Uygulama } \\
\text { Ameliyat Sonrası Hasta Bakımı } \\
\text { (1. Senaryo) } \\
\text { - Monitör göstergelerini bilme } \\
\text { - Yaşam bulgularını alma } \\
\text { - } \quad \text { Kalğer seseslerinini değegrerlendirme } \\
\text { - Yara yeri değerlendirmesirme } \\
\text { - Dren ve idrar takibi yapma } \\
\text { - Periferik nabızları değerlendirme } \\
\text { - Foley sonda uygulaması }\end{array}$} \\
\hline \multicolumn{3}{|c|}{$\begin{array}{l}\text { İleri Yaşam Desteği Uygulaması } \\
\text { (2. Senaryo) } \\
\text { • Kalp masajı yapma } \\
\text { • Hava yolu açılı̆ğını sağlama } \\
\text { • Ambu ile oksijen verme } \\
\text { - Defibrilatör cihazını kullanma } \\
\text { - İlaç uygulaması yapma }\end{array}$} \\
\hline \multicolumn{3}{|c|}{$\begin{array}{l}\text { Tablo 2. Öğrenci Memnuniyeti ve Öğrenmed } \\
\text { Kendine Güven Ölçeği Güvenirlik Analizi }\end{array}$} \\
\hline Alt Boyutlar & $\begin{array}{c}\text { Madde } \\
\text { sayisı }\end{array}$ & $\begin{array}{l}\text { Cronbach's Alpha } \\
\text { (İç tutarlılık) }\end{array}$ \\
\hline $\begin{array}{l}\text { Öğrenci } \\
\text { Memnuniyeti }\end{array}$ & 5 & 0.93 \\
\hline $\begin{array}{l}\text { Öğrenmede } \\
\text { Kendine Güven }\end{array}$ & 8 & 0.83 \\
\hline
\end{tabular}

"Bu simülasyon uygulamasının dahili ve cerrahi alanları öğrenmem için gerekli kritik bilgi içeriğini kapsadığından eminim" ve "klinik alandaki sorumluluklarımı yerine getirmek için bu simülasyondan gerekli bilgileri edindiğime ve becerilerimi geliştirdiğimden eminim" maddelerinde de yüksek oranda katılıyorum yanıtı verildiği tespit edildi (\%46.2 - \%43.1).

$\mathrm{Bu}$ çalışmadan elde edilen Öğrenci Memnuniyeti ve Öğrenmede Kendine Güven Ölçeği'nin minumum, maksimum ve ortalama değerleri Tablo 4'te sunuldu. Öğrencilerin memnuniyet alt bölümünden ortalama $20.72 \pm 4.00$ puan aldıkları görüldü. Öğrencilerin eğitim sonrası kendine güven ölçeğinden ortalama olarak $29.60 \pm 4.98$ puan aldıkları belirlendi. Toplam ölçek puanının ise maksimum 61.00 puan üzerinden $50.32 \pm$ 8.65 olduğu saptand.

\section{Tartış̧ma}

Simülasyona dayalı eğitim, klinik becerilerin tekrarına izin veren, nadir görülen ve yüksek risk taşıyan klinik durumların deneyimlenmesine firsat tanıyan bir yöntemdir. Simülasyona dayalı eğitimin en önemli avantaj1, ögrencilere gerçek klinik ortamlara benzer ortamlarda, gerçek hasta gibi davranan maketlerle çalışma olanağı sunmasıdır. Bunu sağlarken de hasta

güvenliğini koruyan, uygulayarak öğrenme yolu ile beceride yetkinliği arttıran, hastaya zarar verme korkusu yaşatmadan öğrenme imkânı sunan bir öğretim yöntemi olmaktadır. Hemşirelik eğitiminde simülasyon yönteminin etkinliğinin değerlendirildiği bir sistematik incelemede, 17 çalışmanın 12'sinde bilgi, psikomotor beceri ve iletişim becerilerinin kazandırılmasında simülasyon ile eğitimin etkili olduğu belirtilmiştir. Aynı incelemede, 6 çalışma sonucunda simülasyonun öğrencilerin memnuniyet ve öz güven düzeylerinde artma sağladığı gösterilmiştir [7]. Bu güncel çalışmada, öğrencilerin yüksek risk içeren ameliyat sonrası erken dönem hasta bakımı ve nadir görebilecekleri miyokard infarktüsü senaryolarını simülatörde deneyimleme firsatı sunulmuştur. Çalışmadan elde edilen sonuçlara göre simülasyon entegre edilmiş eğitimin öğrencilerin memnuniyet ve öğrenmede kendine güvenlerine olumlu katk1 sağladığı tespit edilmiştir. Çalışma ile paralellik gösteren Ömer' in yapmış olduğu çalışmada aynı sonuçları desteklemektedir [8].

Literatürde faklı değişkenler ile simülasyon eğitiminin etkinliği değerlendirilmiştir. Kim ve Park'ın yaptığ çalışmada simülasyon uygulaması ile öğrencilerin benlik saygısı ve kolektif etkinlik arasında pozitif ilişki, stres düzeyiyle de negatif yönlü ilişki olduğunu ortaya koymuştur [9]. Mezuniyet öncesi simülasyon uygulaması yapan hemşirelik öğrencilerinin görüşlerinin değerlendirildiği bir çalışmada ise öğrencilerin bu uygulamayı oldukça yararlı ve kolaylaştırıcı olduğunu belirttikleri görülmüştür [10]. Crowe ve ark. simülasyon uygulaması yapan hemşirelerde 3 aylık takip süresinde özgüven ve bilgi seviyesinde istatistiksel olarak anlamlı artış olduğunu göstermiştir [11]. Lee ve ark. tarafından yapılan pilot çalışmada simülasyon uygulaması ve video ile öğretim teknikleri karşılaştırılmış ve iki grup arasında bilgi, özgüven ve kortizol seviyeleri karşılaştırılmıştır [12]. 
Tablo 3. Öğrenci Memnuniyeti ve Öğrenmede Kendine Güven Ölçeğine Verilen Yanıtların Dağlımı

\begin{tabular}{|c|c|c|c|c|c|c|}
\hline \multirow[t]{2}{*}{ Ölçek Maddeleri } & \multirow[t]{2}{*}{ 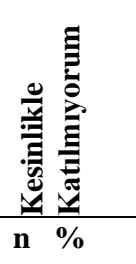 } & \multirow[t]{2}{*}{ 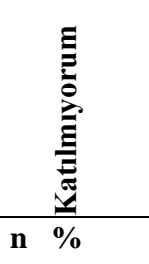 } & 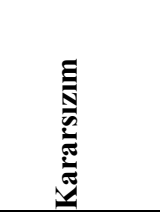 & 至 & 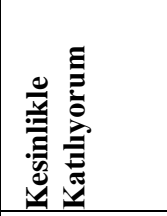 & \multirow[t]{2}{*}{$\begin{array}{l}\infty \\
0 \\
0 \\
0\end{array}$} \\
\hline & & & n $\%$ & n $\%$ & n $\%$ & \\
\hline \multicolumn{7}{|l|}{ Öğrenci Memnuniyeti } \\
\hline $\begin{array}{l}\text { M1: Simülasyonda kullanılan öğretim } \\
\text { yöntemleri yararlı ve etkiliydi. }\end{array}$ & $1(\% 0.8)$ & $7(\% 5,4)$ & $11(\% 8.5)$ & $55(\% 42,3)$ & $56(\% 43,1)$ & $4.21 \pm 0.87$ \\
\hline $\begin{array}{l}\text { M2: Simülasyon dahili ve cerrahi } \\
\text { alanlardaki öğrenmemi } \\
\text { için çok çeşitli öğrenme matirmeryalleri } \\
\text { ve aktiviteleri sağladı. }\end{array}$ & $2(\% 1.5)$ & $12(\% 9.2)$ & $18(\% 13.8)$ & $56(\% 43.1)$ & $42(\% 32.3)$ & $3.95 \pm 0.98$ \\
\hline $\begin{array}{l}\text { M3: } \quad \text { Eğitimcinin simülasyonu } \\
\text { öğretme yönteminden hoşlandım. }\end{array}$ & $1(\% 0.8)$ & $8(\% 6.2)$ & $9(\% 6.9)$ & $57(\% 43.8)$ & $55(\% 42.3)$ & $4.20 \pm 0.87$ \\
\hline $\begin{array}{l}\text { M4: Simülasyonda kullanılan öğretim } \\
\text { materyalleri motive ediciydi ve } \\
\text { öğrenmeme yardımcı oldu. }\end{array}$ & $1(\% 0.8)$ & $4(\% 3.1)$ & $20(\% 15.4)$ & $49(\% 37.7)$ & $56(\% 43.1)$ & $4.19 \pm 0.86$ \\
\hline $\begin{array}{l}\text { M5: Eğitimcinin simülasyonu } \\
\text { öğretme tarzı benim öğrenme tarzıma } \\
\text { uygundu. }\end{array}$ & $1(\% 0.8)$ & $8(\% 6.2)$ & $14(\% 10.8)$ & $54(\% 41.5)$ & $53(\% 40.8)$ & $4.15 \pm 0.90$ \\
\hline \multicolumn{7}{|l|}{ Öğrenmede Kendine Güven } \\
\hline $\begin{array}{l}\text { M6: Eğitimcimin bana sunduğu } \\
\text { simülasyon uygulamasının içeriğini } \\
\text { tam olarak öğrendiğimden eminim. }\end{array}$ & $3(\% 2.3)$ & $6(\% 4.6)$ & $37(\% 28.5)$ & $50(\% 38.5)$ & $34(\% .262)$ & $3.81 \pm 0.95$ \\
\hline $\begin{array}{l}\text { M7: Bu simülasyon uygulamasının } \\
\text { dahili ve cerrahi alanları öğrenmem } \\
\text { için gerekli kritik bilgi içeriğini } \\
\text { kapsadığından eminim. }\end{array}$ & $3(\% 2.3)$ & $4(\% 3.1)$ & $25(\% 19.2)$ & $60(\% 46.2)$ & $38(\% 29.2)$ & $3.96 \pm 0.90$ \\
\hline $\begin{array}{l}\text { M8: Klinik alandaki sorumluluklarımı } \\
\text { yerine getirmek için bu } \\
\text { simülasyondan gerekli bilgileri } \\
\text { edindiğime ve becerilerimi } \\
\text { geliştirdiğimden eminim. }\end{array}$ & $4(\% 3.1)$ & $5(\% 3.8)$ & $28(\% 21.5)$ & $56(\% 43.1)$ & $37(\% 28.5)$ & $3.90 \pm 0.96$ \\
\hline $\begin{array}{l}\text { M9: Eğitimcilerim bu simülasyonu } \\
\text { öğretmek için yararlı kaynaklar } \\
\text { kullandılar. }\end{array}$ & $4(\% 3.1)$ & $7(\% 5.4)$ & $18(\% 13.8)$ & $59(\% 45.4)$ & $42(\% 32.3)$ & $3.98 \pm 0.98$ \\
\hline $\begin{array}{l}\text { M10: } \mathrm{Bu} \text { simülasyondan ne } \\
\text { öğrenmem gerektiğini bilmek öğrenci } \\
\text { olarak benim sorumluluğumdur. }\end{array}$ & $4(\% 3.1)$ & $2(\% 1.5)$ & $17(\% 13.1)$ & $61(\% 46.9)$ & $46(\% 35.4)$ & $4.10 \pm 0.9$ \\
\hline 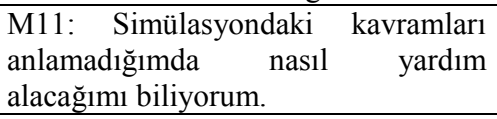 & $3(\% 2.3)$ & $4(\% 3.1)$ & $22(\% 16.9)$ & $65(\% 50.0)$ & $36(\% 27.7)$ & $3.97 \pm 0.88$ \\
\hline $\begin{array}{l}\text { M12: Bu becerilerin kritik yönlerini } \\
\text { öğrenmek için simülasyonu nasıl } \\
\text { kullanacağımı biliyorum. }\end{array}$ & $3(\% 2.3)$ & $2(\% 1.5)$ & $27(\% 20.8)$ & $65(\% 50)$ & $33(\% 25.4)$ & $3.97 \pm 0.88$ \\
\hline $\begin{array}{l}\text { M13: Simülasyon uygulamasının } \\
\text { içeriği ile ilgili ne öğrenmem } \\
\text { gerektiğini söylemek eğitimcimin } \\
\text { sorumluluğudur. }\end{array}$ & $3(\% 2.3)$ & $4(\% 3.1)$ & $17(\% 13.1)$ & $60(\% 46.2)$ & $46(\% 35.4)$ & $1.90 \pm 0.90$ \\
\hline
\end{tabular}

Simülasyon uygulaması sırasında ölçülen kortizol seviyesi, daha yüksek olan deney grubu öğrencilerinin bilgi ve öz güven puanlarının, kontrol grubu öğrencilerinden anlamlı düzeyde yüksek bulunmuş; ayrıca daha önce simülasyon deneyimi olan öğrencilerin öz güvenlerinin daha yüksek olduğu belirlenmiştir. Benzer şekilde Cummings ve Connelly'in, yapmış oldukları çalışmada birinci sınıf ve dördüncü sınıf öğrencilerinin eğitim müfredatına entegre tekrarlı simülasyon deneyimi ile ilgili öz güven, memnuniyet düzeylerinin öğrenmeye etkisini inceledikleri çalışmada dördüncü sınıf öğrencilerinin ölçekten aldığ 1 puan ortalamaları, birinci sınıf öğrencilerinden anlamlı düzeyde yüksek olarak saptanmıştır [13]. 
$\mathrm{Bu}$ durum simülasyona dayalı eğitimin sürekliliğinin öğrenme ve özgüven üzerine olumlu etkisine örnek gösterilebilir.

Çalışmalar olumlu etkileri üzerine yoğunlaşmış olsa da simülasyon uygulamasının öğrencilerin öğrenme ve özgüven skorlarına etkisinin olmadığını bildiren çalışma sonuçları da literatürde yer almaktadır [14-17].

Hemşireler etkili bir sağlık bakımı verebilmek için hastayı doğru değerlendirmeli, etkili müdahaleyi yapabilmelidir. Bunun için özgüven seviyelerinin yüksek olmaları gerekmektedir [18]. Çalışmada kullanılan kendine güven ölçeği Avustralya Sağlık Hizmetleri Kalite ve Güvenlik Komisyonu tarafından sunulan klinik değerlendirmenin yapılabilmesi için gerekli unsurlar ile benzerlik göstermektedir [19]. Bu ölçekten alınan yüksek puanlar başarılı uygulamalar sunulması açısından önemlidir. $\mathrm{Bu}$ çalışmada simülasyon uygulaması sonucunda kendine güven ölçeğinden elde edilen veriler doğrultusunda, öğrencilerin kendine güven düzeylerinin yüksek olduğunu göstermiştir.

\section{Sonuc}

Çalıșmadan elde edilen sonuçlara göre hemşirelik eğitimine entegre edilmiş simülasyon uygulamaları öğrencilerin memnuniyet ve öğrenmede kendine güven puanlarının artışını desteklemektedir. Simülasyon uygulamaları, gerçek klinik ortamlara uygunluğu sayesinde öğrencilerin anksiyete düzeylerini azaltarak öğrenmelerini kolaylaştırırken, özgüvenlerin artmasını sağlamaktadır. Öğrencilerin klinik ortama uyumlarını kolaylaştırarak, daha özgüvenli bir şekilde kariyerlerine hazırlamaktadır. Simülasyon uygulamaları etkili bir öğretim yöntemi olarak kanıtlansa da gerçek hastaya uygulama yapmak kadar etkili olmadığı literatürde ve uzmanlarca bildirilmektedir. $\mathrm{Bu}$ nedenle eğitimciler tarafından simülasyon uygulamaları ile gerçek klinik ortamları birbirine entegre edilerek eğitim programlarının planlanmasının gerekliliği göz ardı edilmemelidir.

\section{Referanslar}

1. Park, H, Yu S. Policy issues in simulation-based nursing education and technology development. Health Policy and Technology 2018; 7(3): 318-321

2. Terzioğlu, F, Kapucu, S, Özdemir, L, Boztepe, H, Duygulu, S, Tuna Z, Akdemir N. Simülasyon yöntemine ilişkin hemşirelik öğrencilerinin görüşleri. Hacettepe Üniversitesi Sağlık Bilimleri Fakültesi Hemşirelik Dergisi 2012; 16-23.

3. Edeer, Durmaz A, Sarıkay,a A. Hemşirelik eğitiminde simülasyon kullanımı ve simülasyon tipleri. Hemşirelikte Eğitim Ve Araştırma Dergisi 2015; 12 (2): 121-125.

4. Bogossianae, F, Cooper S, Kelly M, Levett-Jones T, McKennaae L, Slark J, Seatong P. Best practice in clinical simulation education - are we there yet? A cross-sectional survey of simulation in Australian and New Zealand preregistration nursing education. Collegian 2018; 25(3): $327-$ 334.

5. Karaçay, P, Kaya H. Simülasyonla eğitimde kullanılan Öğrenci Memnuniyeti Ve Öğrenmede Kendine Güven Ölçeği'nin Türkçe'ye uyarlanması. Florence Nightingale Hemșirelik Dergisi 2017; 25(2): 95-103.
6. The International Nursing Association for Clinical Simulation and Learning (INACSL). INACSL standards of best practice: Simulation_Simulation design. Clinical Simulation in Nursing 2016;12: 1- 50.

7. Uzelli, Yılmaz D, Akın, Korhan, E. Hemşirelik eğitiminde simülasyon yönteminin etkinliği: bir sistematik inceleme. Türkiye Klinikleri J Nurs Sci 2017; 9(3):218-226.

8. Ömer, T. Nursing students' perceptions of satisfaction and self-confidence with clinical simulation experience. Journal of Education and Practice 2016;7(5):131-138

9. Kim MY, Park S. Associations of stress, self-esteem, and çölle,ctive efficacy with flow in simulation among nursing students: A descriptive cross-sectional study. Nurse Education Today 2018;71:193-197.

10. Padilha, JM, Machado PP, Ribeiro AL, Ramos JL. Clinical virtual simulation in nursing education. Clinical Simulation in Nursing 2018; 15: 13-18.

11. Crowe S, Ewart L, Derman S. The impact of simulation based education on nursing confidence, knowledge and patient outcomes on general medicine units. Nurse Education Today $2018 ; 29: 70-75$

12. Lee, H, Park J, Kim S, Han J. Cortisol as a predictor of simulation-based educational outcomes in senior nursing students: A pilot study. Clin Simul Nurs 2016;12(2):44-8

13. Cummings C, Connelly LK. Can nursing students' confidence levels increase with repeated simulation activities?. Nurse Education Today 2016; 36: 419-421.

14. Laschinger S, Medves J, Pulling C, McGraw DR, Waytuck B, Harrison MB, Gambeta K. Effectiveness of simulation on health profession students' knowledge, skills, confidence and satisfaction. Int J Evid Based Healthc 2008; 6(3):278-302.

15. Alinier G, Hunt B, Gordon R, Harwood C. Effectiveness of intermediate-fidelity simulation training technology in undergraduate nursing education. J Adv Nurs. 2006; 54(3):359-369.

16. Bearnson, CS, Wiker KM. Human patient simulators: a new face in baccalaureate nursing education at Brigham Young University. J Nurs Educ. 2005;44(9):421-425.

17. Hicks FD, Merritt SL, Elstein AS. Critical thinking and clinical decision making in critical care nursing: a pilot study. Heart and Lung 2003; 32: 169-180.

18. Hart, P, Spira L, Moreno N. Psychometric properties of clinical decision making self-confidence scale. Journal of Nursing Management 2014; 22: 312-322.

19. Australian Commission on Quality and Safety in Healthcare (ACSQHC). National Consensus Statement: Essential Elements for recognizing and responding to clinical deterioration. Canberra Australia 2010.

http://edergi.cbu.edu.tr/ojs/index.php/cbusbed isimli yazarın CBU-SBED başlıklı eseri bu Creative Commons Alıntı-Gayriticari4.0 Uluslararası Lisansı ile lisanslanmıştır. 